\title{
A Study on the Design of Xinghuo Maintenance Workshop for Beijing-Shenyang Passenger High-speed Rail
}

\author{
Zhang Jialu ${ }^{1}$, Zhang Changrui ${ }^{2,}$, , Sun Liang ${ }^{3}$, Tian Yong ${ }^{2}$ \\ ${ }^{1}$ Department of Design, China Railway Design Corporation, Tianjin, China \\ ${ }^{2}$ School of Architecture \& Art Design, Hebei University of Technology, Tianjin, China \\ ${ }^{3}$ Department of Design, China Railway Shanghai Design Institute Group Company Limited, Tianjin, China \\ Email address: \\ zhjilu1979@163.com(Zhang Jialu),zzccrr1979@126.com (Zhang Changrui),380944511@qq.com (Sun Liang), \\ huazhusheji@126.com(Tian Yong) \\ ${ }^{*}$ Corresponding author
}

\section{To cite this article:}

Zhang Jialu, Zhang Changrui, Sun Liang, Tian Yong. A Study on the Design of Xinghuo Maintenance Workshop for Beijing-Shenyang Passenger High-speed Rail. International Journal of Architecture, Arts and Applications. Vol. 3, No. 5, 2017, pp. 68-72. doi: $10.11648 /$ j.ijaaa.20170305.11

Received: May 6, 2017; Accepted: August 26, 2017; Published: September 26, 2017

\begin{abstract}
This paper makes an in-depth analysis on the design of the super large-scale maintenance workshop for Beijing-Shenyang Passenger High-speed Rail maintenance workshop of Beijing-Shenyang Passenger High-Speed Rail, and demonstrates its important position in industrial architecture referring to the significant status of Beijing-Shenyang Passenger High-speed Rail in China's railway construction. Through the study on the design process of architecture, structure and construction of the maintenance workshop, and the research on the fireproof performance, this thesis provides a useful reference value and academic significance for the design and construction of the super large maintenance workshop for high-speed rail in China.
\end{abstract}

Keywords: Beijing-Shenyang High-Speed Railway, High-Speed Railway Maintenance Workshop, Engineering Design

\section{General Condition}

Beijing-Shenyang Passenger High-speed Rail ("Rail" in short below) is one of the important rails on building. In the future, it will undertake main passenger distribution function between Bohai economic zone and the northeast industrial base and become transportation links in North China, East China, South China and Northeast Economic Zone. The whole line runs through three provinces and cities, from the capital Beijing, extending to the northeast through Chengde City, Chaoyang City, Jinzhou City and Fuxin City, and ultimately reaches its provincial capital, Shenyang. The Rail dedicated line is an important part of the "four vertical and four horizontal [1]" (Railway Planning) network China, and will become the important traffic artery connecting Shanhaiguan and abroad.

Based on such an important high-speed railway project, large maintenance facilities are also very important. The newly built Beijing-Shenyang Passenger High-speed Rail
Xinghuo Maintenance Workshop is the largest maintenance base for rail. The total construction area of the project is $50,697 \mathrm{~m}^{2}$, which can provide inspection and repair services for 10 lines and 20 trains at the same time. Xinghuo Maintenance Workshop consists of three parts, in addition to the main span (column spacing of central main space) of maintenance workshop, both sides across have logistics space with the auxiliary function.

The construction area of maintenance workshop base is $39,644 \mathrm{~m}^{2}$, the construction area of two side span is 11,053 $\mathrm{m}^{2}$, and the height of main building is $14.6 \mathrm{~m}$. The main span of maintenance workshop is the bent frame structure. Arched steel roof of reinforced concrete rectangular column bearing to achieve the spatial design of large span and the side span structure with reinforced concrete frame system, enhance the function of the stability and maintenance of structure integration. Along the direction of the track, the main span length of $468.0 \mathrm{~m}$ can meet the requirement of maintenance for two 8-section rails [2]. On the vertical direction, the main 
space is divided into three spans: $33.0 \mathrm{~m}+33.0 \mathrm{~m}+18.0 \mathrm{~m}$, each side of the span is $9.0 \mathrm{~m}$, where 10 sets of rails can park at the same time. (See Figure 1, 2)

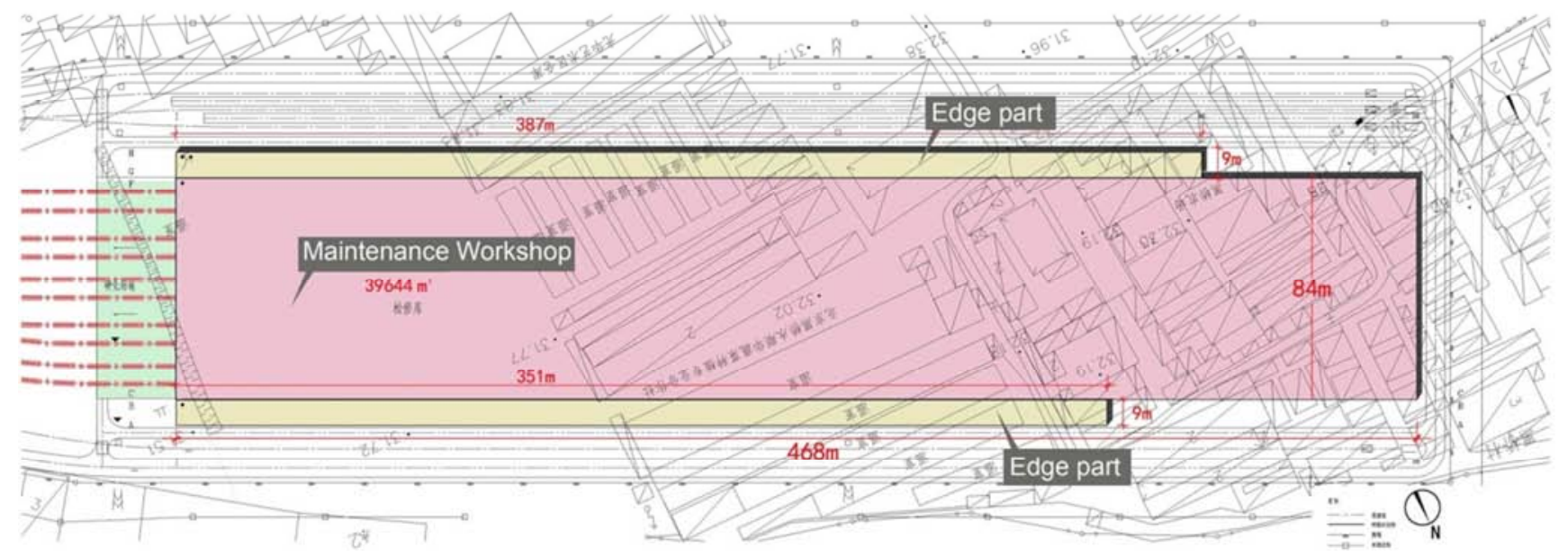

Figure 1. The plant of the train check library.
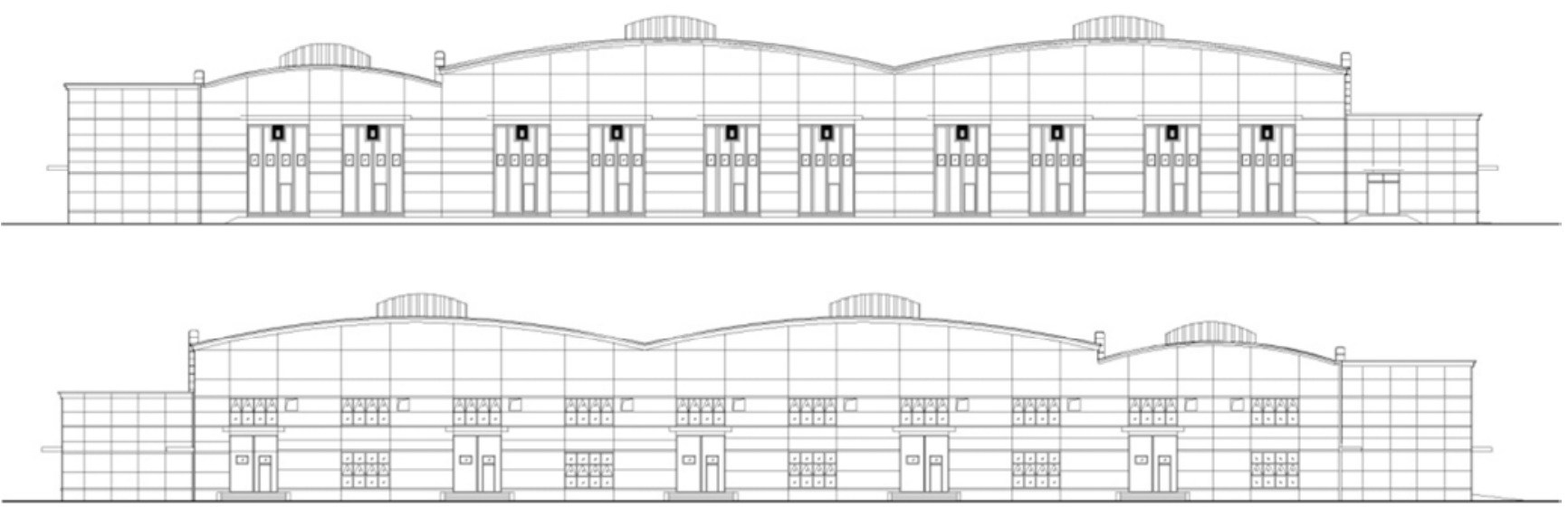

Figure 2. East and west elevation of the train check library.

The main span of the maintenance workshop is a monolayer space, and the track elevation is $+0.000 \mathrm{~m}$. The main building cornice elevation is $10.9 \mathrm{~m}$, and the highest point of the skylight roof elevation is $14.6 \mathrm{~m}$. The elevation of roof structure on both sides is $8.5 \mathrm{~m}$ and $6.75 \mathrm{~m}$ respectively. The span of"10 lines" maintenance workshop is divided into three spans, within which the adjacent track spacing is $8.5 \mathrm{~m}$ and $7.0 \mathrm{~m}$, and the net spacing between track and structural column is $5.0 \mathrm{~m}$. (See Figure 3)

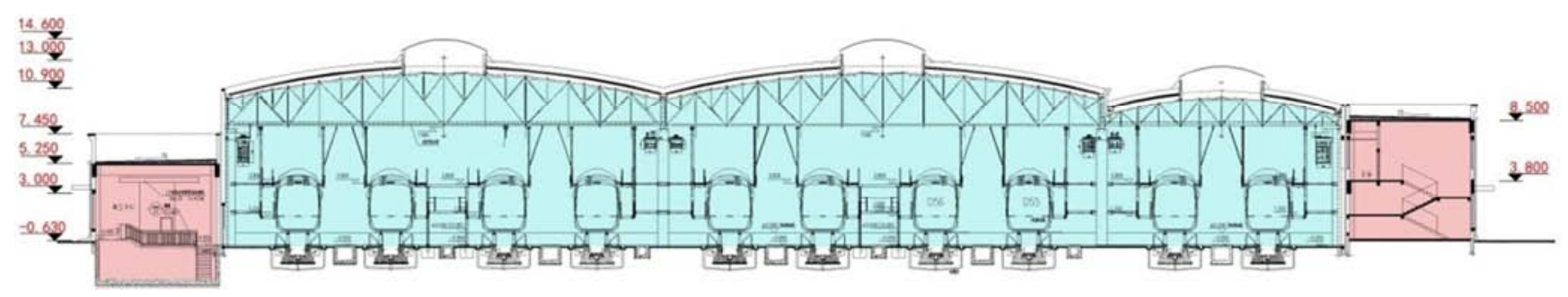

Figure 3. Section of the train check library-1.

\section{Design of Architecture in Detail}

\subsection{Roof Construction Practices}

The main roof of the maintenance workshop adopts light steel roof truss on its base, with $0.65 \mathrm{~mm}$-thick profiled steel liner on it, the polyolefin coating of spun bonded polyethylene film of not less than $0.25 \mathrm{~mm}$ as a vapor barrier layer, insulating layer with $100 \mathrm{~mm}$ thick glass wool insulation board, waterproof and water vapor permeable layer adopts $0.49 \mathrm{~mm}$ thick spun bonded polyethylene and polypropylene film, roof surface layer thickness of $0.8 \mathrm{~mm}$ YX70-468 type fluorocarbon spraying aluminum zinc plate. (See Figure 4). 


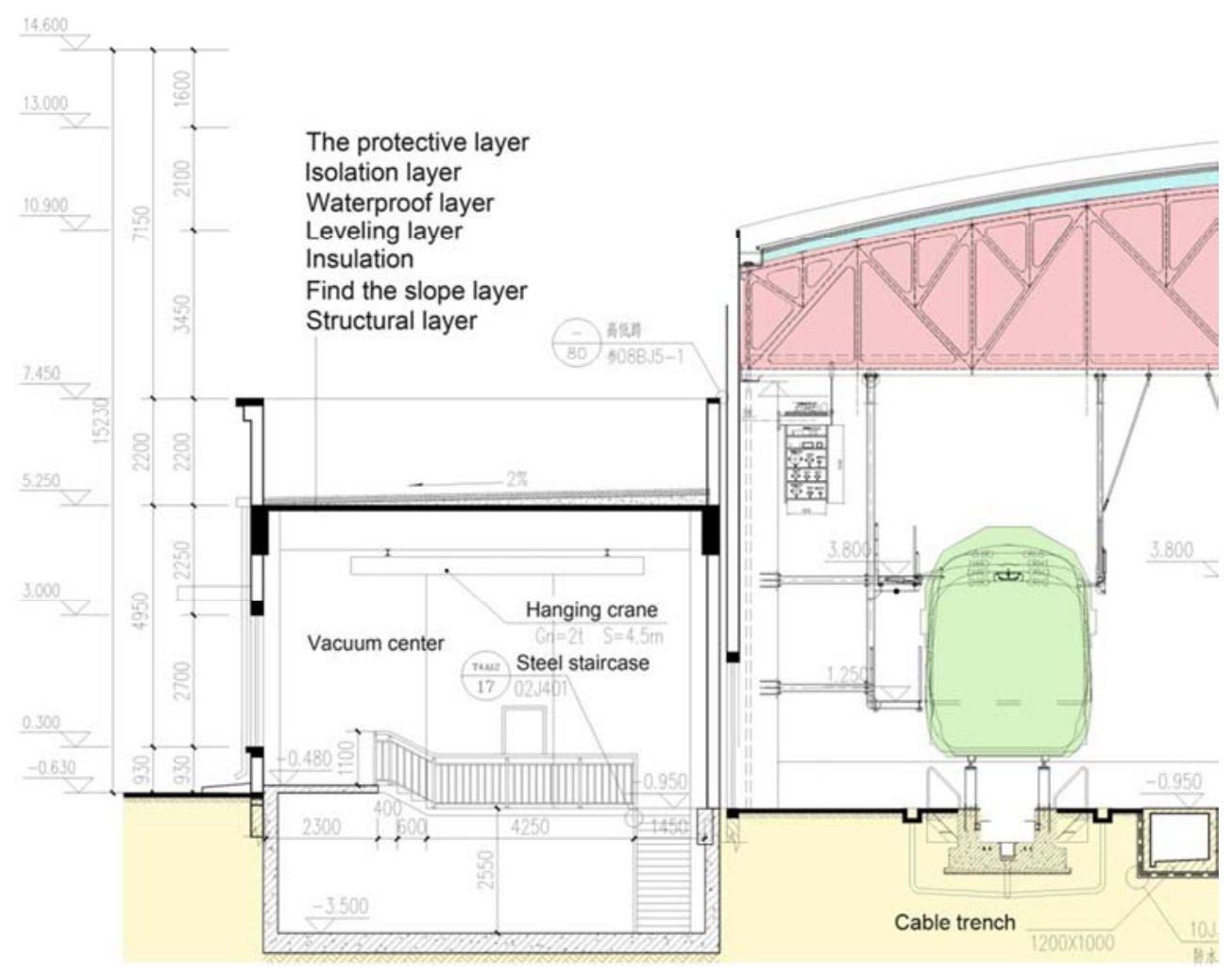

Figure 4. Section of the train check library-3.

\subsection{Construction Practice of Repair Ditch}

The design of the maintenance ditch of the rail adopts the independent "Y" type of reinforced concrete foundation bearing, the bottom thickness of the foundation is $1 \mathrm{~m}$, the double row reinforced cast-in-place casting. Flank is the "L" type $300 \mathrm{~mm}$-thick reinforced concrete cast-in-place trench wall. 700mm-high track pier is erected on the base, foot board installed in the waist of the bridge pier for convenient maintenance, tracks laid on the top of the bridge. (see Figure 5)

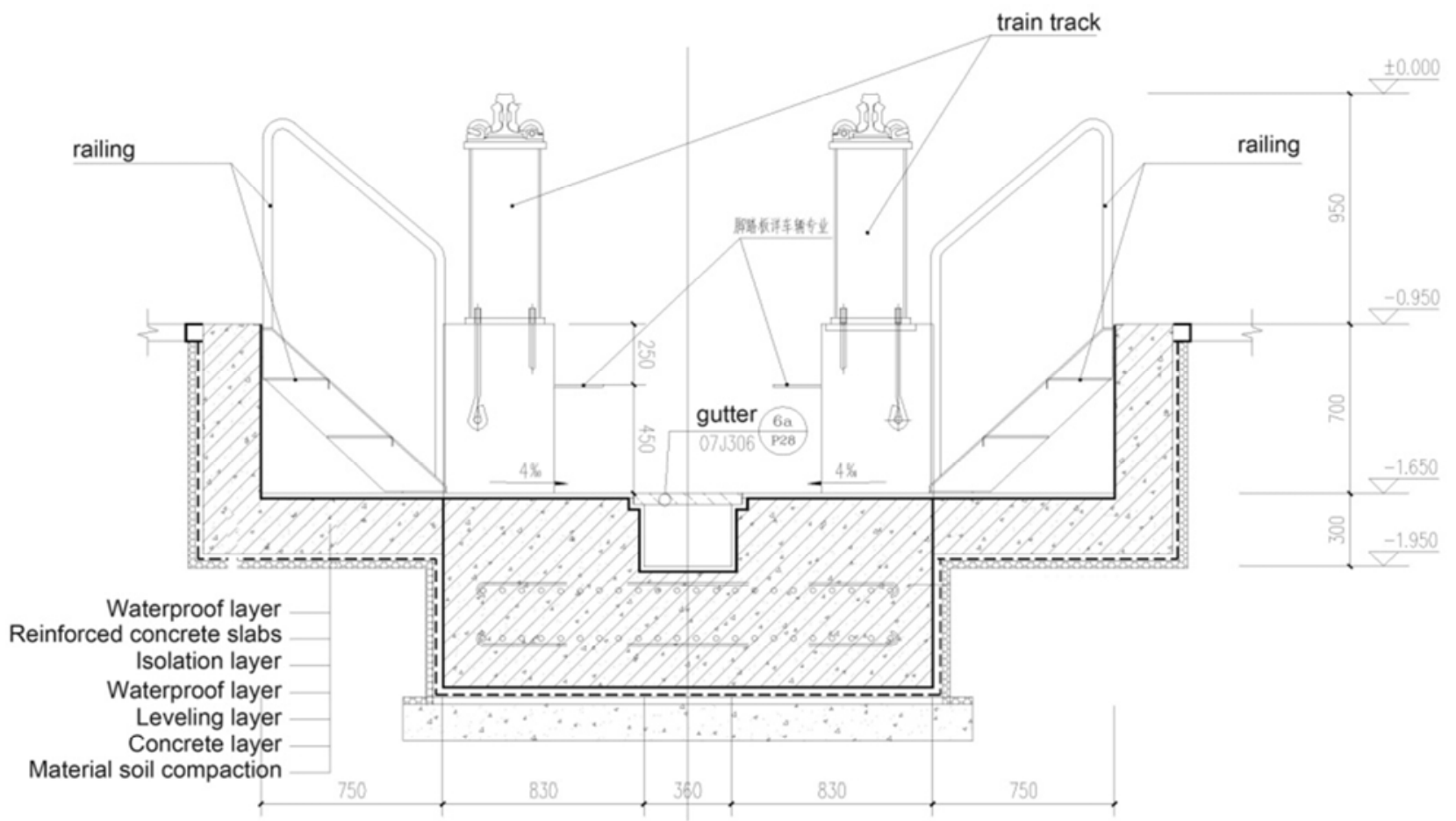

Figure 5. Sectional view of entrance of maintenance channel. 


\section{The Research on the Fireproof Strategy of Maintenance Workshop}

In the design process, according to the "Code for Fireproof Design of Railway Engineering" (TB 10063-2007) (Ed. 2012) [3] standard, the fire risk of maintenance workshop is set to class $\mathrm{C}$ workshop, the fireproof grade is second. Fire extinguishing system is installed in maintenance workshop, according to the "code fireproof code for architectural design" (GB 50016-2014) [4] maximum fireproof zone should be controlled within the range of $16,000 \mathrm{~m}^{2}$, and the safe evacuation length is $80.0 \mathrm{~m}$. In the main span range, when maintenance operations on the rails, due to rail auxiliary room, personnel in the vertical direction have evacuation difficulties, and extended track evacuation distance is too long, how to reconcile the conflict between graphic design and the national standard is an important subject in fire safety strategy research. So, in order to judge the feasibility of this design, the researchers need to carry out additional proof of the project about the lack of fireproof code.

\subsection{Introduction of Fireproof Design}

When analyzing fireproof issue, the aim of "fireproof design plan [5] "is to guarantee the following situations: first, the prevention of fire; two, find fire in time; three, sensitive trigger alarm system; four, orderly evacuation of personnel; five, control and elimination of fire. Therefore, when the requirements of "Fireproof Code of Architecture Design [6]" cannot be meet by "design plan of fireproof", problems will be divided into several technical plan modules, which can not only ensure the safety of personnel evacuation but also control the fire, and the losses will be reduced to a minimum and the safety of the structure can be quaranteed [7].

\subsection{Judgment of Personnel Evacuation Safety}

The ultimate goal for the study on the fireproof performance of building is to ensure the safe evacuation of personnel, to make sure the whole building system (covering fire system) can provide sufficient time for all personnel to escape from the fire and the damage related. The researchers use parameter magnitude-Tescape [8] to indicate the time needed for personnel evacuation, and parameter magnitude-Trisk [9] to the time beyond human tolerance limit with fire development. And the third parameter magnitude-Ts, indicating the changing relationship between the two, is the safety margin for personnel evacuation in fireproof design. Then the researchers can get a parameters formula about safe evacuation when fire happens:

$$
\text { Tescape }+ \text { Ts }+ \text { Trisk }
$$

The time dimension of Tescape can be divided into three stages: awareness of the fire, evacuation operations, evacuation operations to reach the security area. In the fire accident, Ts represents a safety factor that is needed to eliminate the uncertainty of the fire. In the analysis of the hypothesis of the fire scenario, the researchers will locate the typical fire location in the A to $\mathrm{F}$ point, as shown in Figure 8, the six virtual fire points covering the most unfavorable evacuation point in the entire maintenance space. If fire starts from any one of the six points mentioned above (possibility of fire on multi points is considered negligible) [10], by calculating the evacuation (Tescape) the longest time is $476 \mathrm{~s}$, and that in the premise of automatic fire extinguishing device failure, the shortest time (Trisk) for the fire danger area is 1200 s by measuring, which is far beyond the longest time required for evacuation. According to the analysis above, at any point of large space in the maintenance workshop, fire safety evacuation has sufficient safety margin (Ts). (see Figure 6).

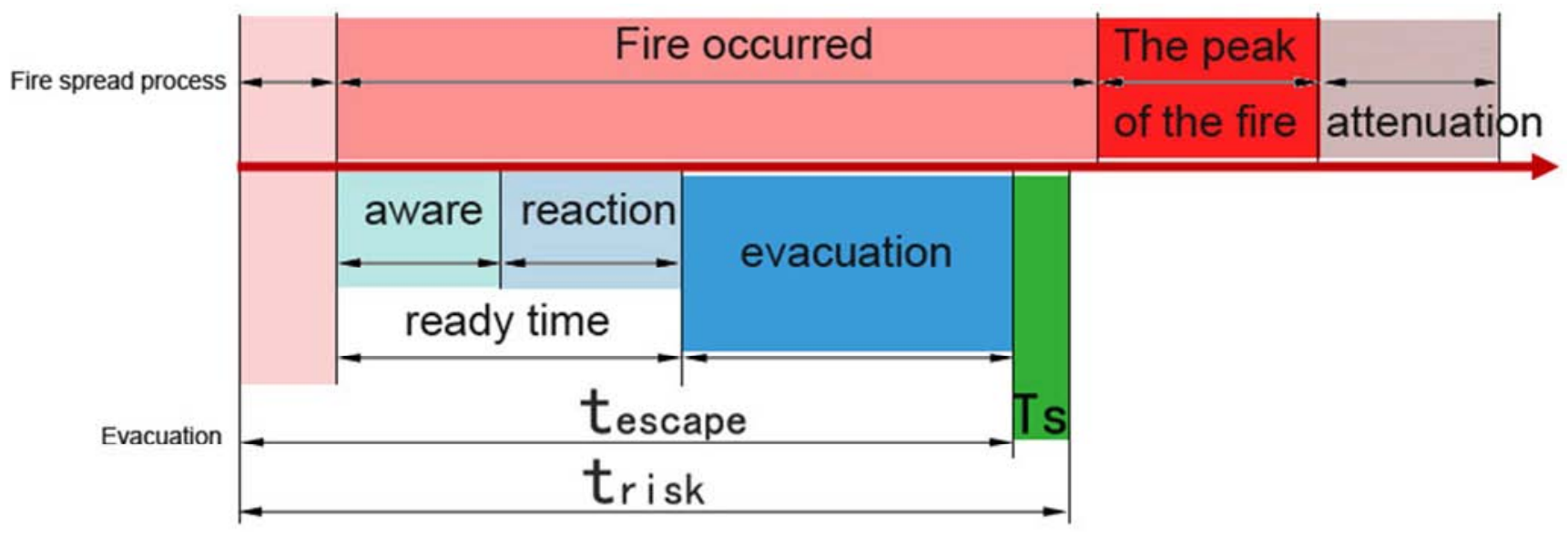

Figure 6. Parameter Analysis of Fire Development and Personnel.

\subsection{Fire Partition Settings}

In view of the analysis above, the researchers have identified the following criteria for the inspection of the overall fireproof area partition:

(1) The space between the main workspace and the two sides which has no evacuation condition is incorporated into an expanded fireproof area. 
(2) In the first layer, the space with no independent evacuation entrance will be divided into independent fireproof space, which should be isolated from main workshop space with no less than 3.0h fireproof wall, and the open holes should be set up with A-class fire doors and windows.

(3) In the expanded fireproof zone, the auxiliary workshop and spare parts storage space, with higher fire risk should be equipped with no less than $2.0 \mathrm{~h}$ fireproof wall, A-class fireproof doors, windows.

(4) In the second layer, the office space is set up with fireproof areas according to the current code. Between main workshop and these areas, no less than 2.0h fireproof wall, A-class fireproof doors, and windows should be equipped with.

\section{Conclusion}

Through the introduction of the design of Xinghuo Maintenance Workshop for Beijing-Shenyang Passenger High-speed Rail, this thesis analyzes the design of super-large space and the strategy of fireproof of 10-line high-speed rail workshop from the engineering point of view. From the professional perspective of the railway construction, this thesis makes an in-depth analysis on the configuration of space function and fireproof strategy of the maintenance workshop from a professional perspective, and provides a reference model for the design of maintenance space for multi-line rail. It is hoped that this thesis can make some contributions to effectively promote the engineering efficiency of national infrastructure construction in the present era of high-speed rail.

\section{References}

[1] http://baike.baidu.com/link?url=iyzMXrVKvUDYHUhz5xpH x4ZTpWuWoWTPsKWulOEsZEpLhSty01Lmm8nbAa6pP2f XBHlg8ZGmLwSyaLxkq6Zg72tj_bvX9kWK7c1Ocf0dO6t57 fp5BwL1SrkhRL3y2wovple29wvODGwo7uGm5Y094cqtz30 c9j4XsF80syyoOfidlwKWCkBYktqWAGhPXN_vHRio2ZtpS ZBAY0ZfnsrPBHkparKAk3jcKiny5RUW2fW

[2] Tienan Guo, Chinese fire handbook, Shanghai Science and Technology Press, Volume III, 2006.12, P. 726.

[3] China Railway Administration, Code for fire protection design of railway engineering (TB 10063-2007), (2012 edition).

[4] Tianjin Fire Research Institute, Architectural design code for fire protection (GB 50016-2014), (2005 edition).

[5] Research Progress and Development Direction of Steel Structure Fireproof Coatings [J]. Geng Hezhong. Fire Fighting Technology and Product Information. 2007 (10).

[6] Study on Performance Design of Building Fire [J]. Tu Jiapeng, Dong Weixin, Zhou Ming. Low Temperature Construction Technology. 2016 (10).

[7] Australian Building Codes Board, FCRC Fire Engineering Guidelines(2006 edition).

[8] Application of Fireproof Performance Design in Buildings [J]. Wang Yan-shan. Technology Innovation and Application. 2016 (32).

[9] The fire test method for full-size model fire protection of external thermal insulation system [J]. Ji Guangqi, Zhu Chunling, Zhang Lequn.

[10] Study on Human Evacuation Method in Building Fire [J]. Xiao Guoqing, Liao Guangxuan. Chinese Journal of Safety Science. 2006 (02). 